\title{
Early ( $\leq 30$ Days), Late (31-360 Days) and Very Late (> 360 Days) Stent Thrombosis in Patients with Insulin-Treated versus Non-Insulin-Treated Type 2 Diabetes Mellitus: A Meta-Analysis
}

Wei Chen · Yubin $\mathrm{Wu} \cdot$ Yubao $\mathrm{Hu}$

Received: March 23, 2018 / Published online: April 11, 2018

(C) The Author(s) 2018

\section{ABSTRACT}

Introduction: At this time in 2018, with type 2 diabetes mellitus (T2DM) and coronary artery disease (CAD) still on the rise, the post-percutaneous coronary interventional (PCI) outcomes observed in patients with diabetes mellitus who are on insulin therapy (ITDM) and those who do not require insulin (NITDM) are still controversial and require further investigation. Considering this idea to be of particular interest to the readers, as well as being an important issue in interventional cardiology, we aimed to systematically assess early ( $\leq 30$ days), late (31-360 days) and very late (>360 days) stent thrombosis in patients with ITDM and NITDM following drug-eluting stent (DES) implantation.

Methods: Well-known online databases (the Cochrane, EMBASE and MEDLINE databases and http://www.ClinicalTrials.gov) were searched for relevant English publications based on

Enhanced Digital Features To view enhanced digital features for this article, go to https://doi.org/10.6084/ m9.figshare.6086210.

W. Chen · Y. Wu $(\bowtie) \cdot$ Y. Hu

Department of Cardiology, Guilin People's Hospital,

No. 12, Wenming Road, Guilin 541002, Guangxi,

China

e-mail: wyb201819@163.com
ITDM and NITDM and stent thrombosis following PCI using specific terms. Early stent thrombosis, late stent thrombosis and very late stent thrombosis were the clinical outcomes. The main analysis was carried out using the latest version of the RevMan software (version 5.3) whereby odds ratios (OR), and 95\% confidence intervals (CI) were generated.

Results: A total of 8524 participants with T2DM (2273 participants were on insulin therapy and 6251 participants were not) were included. Results of this analysis showed early stent thrombosis to be significantly higher in patients with ITDM (OR 1.81, 95\% CI 1.04-3.15; $P=0.04)$, whereas late and very late stent thromboses were not significantly different following PCI with DES in diabetic patients with versus without insulin therapy (OR 1.44, 95\% CI $0.73-2.84, P=0.30$ and OR $0.80,95 \%$ CI $0.33-1.92, P=0.62$, respectively). Late stent thromboses associated exclusively with everolimus-eluting stents (EES) and paclitaxel-eluting stents (PES) were not significantly different in patients with ITDM and NITDM.

Conclusion: Following PCI with DES, early stent thrombosis was significantly higher in patients with ITDM. However, late and very late stent thromboses were not significantly different in patients with type 2 diabetes mellitus who were treated with or without insulin. Comparison with individual DES was not sufficiently powerful to reach a conclusion. 
Keywords: Coronary artery disease; Drugeluting stents; Early stent thrombosis; Insulintreated type 2 diabetes mellitus; Late stent thrombosis; Percutaneous coronary intervention

$\begin{array}{ll}\text { Abbreviations } \\ \text { DAPT } & \text { Dual antiplatelet therapy } \\ \text { DES } & \text { Drug-eluting stents } \\ \text { PCI } & \text { Percutaneous coronary intervention } \\ \text { ST } & \text { Stent thrombosis } \\ \text { T2DM } & \text { Type } 2 \text { diabetes mellitus }\end{array}$

\section{INTRODUCTION}

At this time in 2018, with type 2 diabetes mellitus (T2DM) and coronary artery disease (CAD) still on the rise [1], the post-percutaneous coronary interventional (PCI) outcomes observed in patients with diabetes mellitus who are on insulin therapy (ITDM) and those who do not require insulin (NITDM) are still controversial and require further investigation.

In October 2015, Bundhun et al. published an interesting meta-analysis based on the comparison of outcomes observed in patients with ITDM and NITDM following PCI [2]. Recently, we came up with a new idea based on stent thrombosis in patients with ITDM versus NITDM who were treated with drug-eluting stents (DES).

Considering this idea to be of particular interest to the readers, as well as being an important issue in interventional cardiology, we aimed to systematically assess early ( $\leq 30$ days), late (31-360 days) and very late (>360 days) stent thrombosis in patients with ITDM and NITDM following DES implantation.

\section{METHODS}

\section{Searched Materials (Searched Databases and Terms)}

Well-known online databases (the Cochrane, EMBASE and MEDLINE databases and http:// www.ClinicalTrials.gov) were searched for relevant English publications based on ITDM and
NITDM and stent thrombosis following PCI using the terms:

1. Diabetes mellitus and percutaneous coronary intervention/PCI;

2. Diabetes mellitus and coronary angioplasty;

3. Drug-eluting stents and diabetes mellitus;

4. Diabetes mellitus and stent thrombosis;

5. Insulin-treated diabetes mellitus and percutaneous coronary intervention.

These searched terms were applied to each of the electronic databases, and the searched outcomes were carefully assessed for relevant publications that would be suitable for this current research topic and would be expected to contain data to possibly be used for this analysis.

\section{Inclusion and Exclusion Criteria}

The two major inclusion criteria were:

1. Research papers comparing patients with ITDM and NITDM following PCI;

2. With reference to the above criterion (1), early, late and/or very late stent thrombosis should be reported among the endpoints.

Exclusion criteria were:

1. Research paper dealing with patients with T2DM without further dividing the patients into ITDM and NITDM;

2. Early, late or very late stent thromboses were not reported; instead, definite and/or probable stent thromboses were reported;

3. Research that involved patients with type 1 diabetes mellitus;

4. Duplicated studies;

5. Review articles, meta-analyses and letters to editors.

\section{Definitions of Specific Terms}

ITDM was defined as patients with T2DM who required insulin as treatment.

NITDM was defined as patients with T2DM who did not require insulin as treatment, but instead were dependent on oral hypoglycemic agents.

Early stent thrombosis [3] was defined as acute and sub-acute stent thrombosis observed at $\leq 30$ days following PCI. 
Late stent thrombosis [3] was defined as stent thrombosis that occurred after 30 days (31-360 days) following PCI.

Very late stent thrombosis [3] was defined as stent thrombosis that occurred after 360 days following PCI.

\section{Outcomes, Types of Participants, Types of DES and Follow-Up Periods}

The three endpoints of this analysis were early, late and very late stent thrombosis as shown in Table 1.

The follow-up time period varied from 1 to 3 years.

All participants were candidates for T2DM + CAD who underwent revascularization by PCI.

The types of DES varied: everolimus-eluting stents (EES), paclitaxel-eluting stents (PES), sirolimus-eluting stents (SES) and zotarolimuseluting stents (ZES) were used as shown in Table 1.

\section{Data Extraction, Quality Assessment and Statistical Analysis}

Three reviewers, Wei Chen, Yubin $\mathrm{Wu}$ and Yubao $\mathrm{Hu}$, independently extracted the following data:

1. The study type (randomized controlled trials, cohort studies, retrospective studies);

2. The types of participants involved;

3. The total number of participants who were on insulin treatment or were on oral hypoglycemic drugs;

4. The baseline characteristics of the participants;

5. The endpoints (early, late and very late stent thrombosis);

6. The total number of events in each category;

7. The year internal period of patient enrollment;

8. The types of DES reported;

9. The methodologic quality of the trials for assessment.

Table 1 Outcomes, follow-up periods and types of participants

\begin{tabular}{|c|c|c|c|c|}
\hline Studies & Outcomes reported & $\begin{array}{l}\text { Follow-up time period } \\
\text { (years) }\end{array}$ & Types of participants & $\begin{array}{l}\text { Types of } \\
\text { DES }\end{array}$ \\
\hline $\begin{array}{l}\text { Banning et al. } \\
{[6]}\end{array}$ & $\begin{array}{l}\text { Early (acute and sub-acute) and } \\
\text { late ST }\end{array}$ & 1 & $\begin{array}{l}\text { Left main and triple vessel } \\
\text { disease }\end{array}$ & PES \\
\hline Jain et al. [7] & $\begin{array}{l}\text { Early (acute and sub-acute) and } \\
\text { late ST }\end{array}$ & 1 & $\mathrm{CAD}$ & ZES \\
\hline Jiang et al. [8] & Early, late and very late ST & 2 & $\mathrm{CAD}$ & DES \\
\hline $\begin{array}{l}\text { Kereiakes et al. } \\
\text { [9] }\end{array}$ & $\begin{array}{l}\text { Early (acute and sub-acute) and } \\
\text { late ST }\end{array}$ & 1 & $\mathrm{CAD}$ & EES, PES \\
\hline $\begin{array}{l}\text { Nakamura et al. } \\
{[10]}\end{array}$ & Early, late and very late ST & 3 & CAD + hemodialysis & SES \\
\hline Silber et al. [11] & Early, late and very late & 2 & $\mathrm{CAD}$ & ZES \\
\hline Simek et al. [12] & Early, late and very late & 3 & $\mathrm{CAD}$ & $\begin{array}{l}\text { EES, SES, } \\
\text { PES }\end{array}$ \\
\hline
\end{tabular}

Early stent thrombosis: $0-30$ days

Late stent thrombosis: 31-360 days

Very late stent thrombosis: $>360$ days

$S T$ stent thrombosis, DES drug-eluting stents, $C A D$ coronary artery disease, $P E S$ paclitaxel-eluting stents, $E E S$ everolimuseluting stents, $S E S$ sirolimus-eluting stents, $Z E S$ zotarolimus-eluting stents 
Any disagreement that followed was solved by consensus.

The methodologic quality of the trials was assessed based on the criteria recommended by the Cochrane collaboration [4] whereby grades were given in accordance with whether a low, moderate or high risk of bias was reported.

The main analysis was carried out using the latest version of RevMan software (version 5.3) whereby odds ratios (ORs) and 95\% confidence intervals (CIs) were generated.

In this analysis, ORs were used to compare the relative odds of the occurrence of stent thrombosis (early, late and very late), given exposure to insulin treatment. These ORs were also used to determine whether exposure to insulin therapy was a risk factor for stent thrombosis in these patients with T2DM who had previously been implanted with DES.

However, the presence of a positive OR in this case did not necessarily indicate that this association was statistically significant. We also had to consider the CIs and P values to determine significance.

The $95 \% \mathrm{CI}$ is used to estimate the precision of the OR obtained. A large CI indicates a low level of precision of the OR, whereas a small CI indicates higher precision. The CI indicates the level of uncertainty around the measure of effect, which is expressed as an OR in this analysis. Similar to other studies, we have also reported the 95\% CIs in this analysis.

Heterogeneity is a common feature in metaanalyses. Heterogeneity was assessed by the following:

1. The $Q$ statistic test whereby $P \geq 0.05$ was considered statistically significant;

2. The $I^{2}$ statistic test whereby an increasing $\mathrm{I}^{2}$ value signified increasing heterogeneity and a low $I^{2}$ value signified low heterogeneity.

In addition, the statistical model used was based on this heterogeneity value whereby a fixed effects model was used if $I^{2}$ was $\leq 50 \%$ and a random effects model was used if the $I^{2}$ value was $>50 \%$.

Sensitivity analysis was carried out by an expulsion method for comparison with the main results.
Since this analysis involved a small volume of studies, publication bias was better assessed by funnel plots, which could be generated using the RevMan software.

\section{Compliance with Ethics Guidelines}

This meta-analysis, based on previously conducted studies, does not contain any studies with human participants or animals performed by any of the authors. Hence, ethical approval was not required.

\section{RESULTS}

\section{Searched Outcomes and the General Properties of the Included Studies}

The PRISMA guideline was followed [5]. A thorough search of online databases resulted in 6187 publications. Figure 1 shows the flow diagram for the study selection.

Seven publications [6-12] were selected for this analysis, as shown in Fig. 1.

Table 2 lists the studies selected for this analysis.

After a careful assessment of the methodologic quality of the trials, a low-to-moderate risk of bias was observed and graded from $\mathrm{A}$ to $\mathrm{C}$ whereby ' $A$ ' signified low risk of bias, ' $B$ ' signified moderate risk of bias, and ' $\mathrm{C}$ ' signified a high risk of bias.

A total of 8524 participants with T2DM (2273 participants were on insulin therapy and 6251 were not) were included in this analysis.

The period of patient enrollment varied from 2004 to 2012. All the patients received dual antiplatelet therapy (DAPT) following stent implantation. However, the duration of DAPT was not stated.

\section{Participants' Baseline Features}

The participants' baseline features are listed in Table 3.

Mean age of 63.3-67.2 years was reported with a predominance of male patients. Features such as hypertension, dyslipidemia and current 


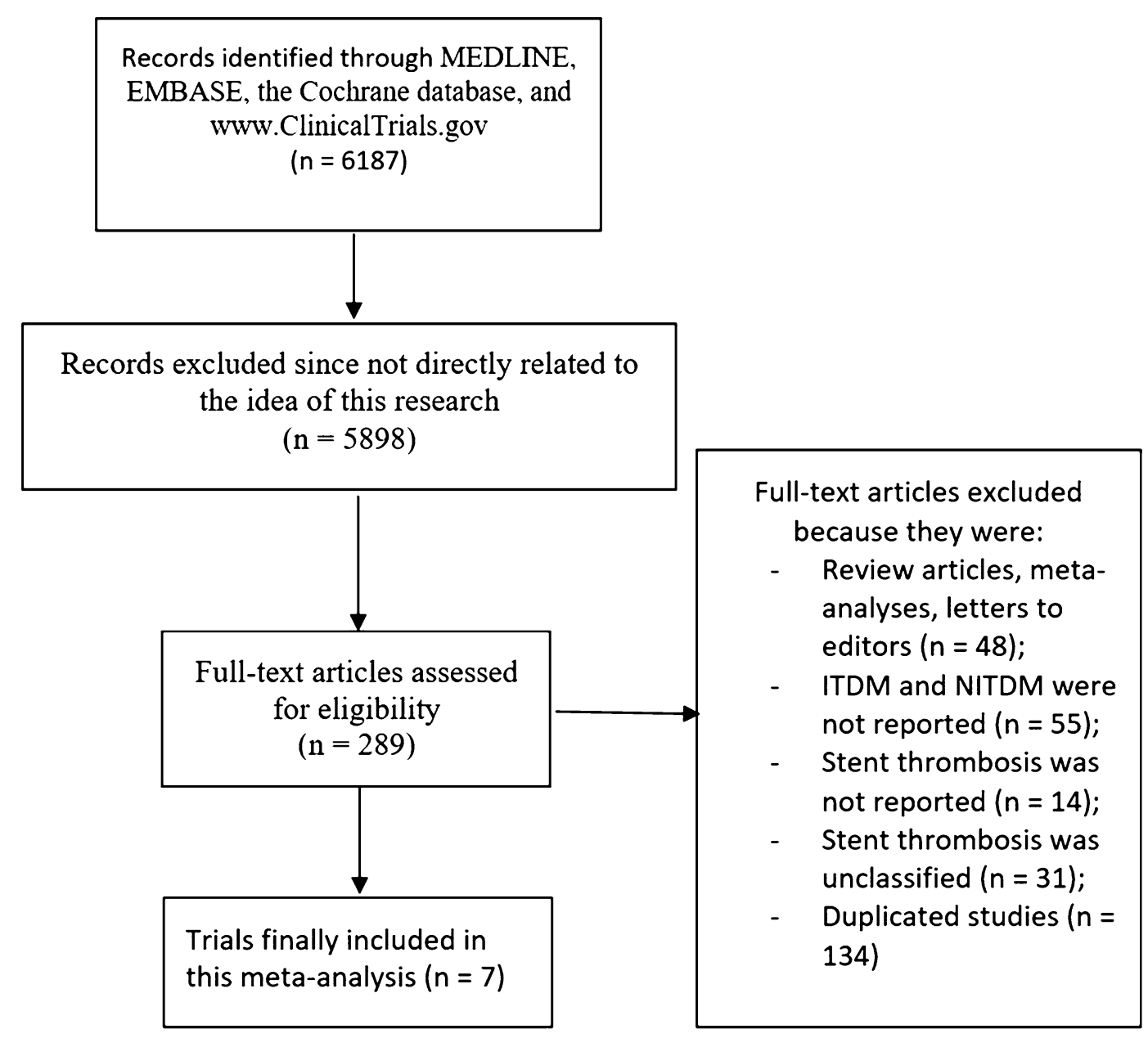

Fig. 1 Flow diagram showing the selection of studies

smoking were also reported in patients with ITDM and NITDM, as shown in Table 3. Overall, there was no significant difference in baseline features between the diabetic patients with and without insulin therapy.

\section{Main Analysis Results}

Results of this analysis showed early stent thrombosis to be significantly higher in patients with ITDM (OR 1.81, 95\% CI 1.04-3.15; $P=0.04$ ), but late stent thrombosis was not significantly different following PCI with DES in diabetic patients with versus without insulin therapy (OR 1.44, 95\% CI 0.73-2.84; $P=0.30$ ), as shown in Fig. 2. Very late stent thrombosis was also not significantly different (OR 0.80, 95\% CI 0.33-1.92; $P=0.62$ ), as shown in Fig. 2.

Late stent thromboses associated with different individual DES subgroups were also analyzed separately. Late stent thromboses associated with PES and EES were also not significantly different between patients with ITDM and NITDM (OR 0.63, 95\% CI 0.18-2.20, $P=0.47$ and OR 0.66, 95\% CI 0.11-3.89, $P=0.65$, respectively), as shown in Fig. 3. Even if late stent thrombosis associated with ZES was significantly higher in patients with ITDM (OR $3.14,95 \%$ CI $1.20-8.20 ; P=0.02$ ), only two studies with an insufficient number of patients comprised this particular subgroup, which was insufficient for reaching conclusions.

Sensitivity analysis was consistent throughout the analysis. 
Table 2 General characteristics of the included studies

\begin{tabular}{|c|c|c|c|c|c|}
\hline Studies & $\begin{array}{l}\text { Patients with } \\
\text { ITDM }(n)\end{array}$ & $\begin{array}{l}\text { Patients with } \\
\text { NITDM }(n)\end{array}$ & $\begin{array}{l}\text { Type of } \\
\text { study }\end{array}$ & $\begin{array}{l}\text { Year of patients' } \\
\text { enrollment }\end{array}$ & $\begin{array}{l}\text { Antiplatelets } \\
\text { used }\end{array}$ \\
\hline Banning et al. [6] & 89 & 142 & RCT & $2005-012$ & DAPT \\
\hline Jain et al. [7] & 644 & 1919 & Cohort & $2005-2007$ & DAPT \\
\hline Jiang et al. [8] & 68 & 132 & Retrospective & 2010-2013 & DAPT \\
\hline Kereiakes et al. [9] & $209+119$ & $577+280$ & $\mathrm{RCT}$ & $2006-2009$ & DAPT \\
\hline $\begin{array}{l}\text { Nakamura et al. } \\
{[10]}\end{array}$ & 200 & 647 & Cohort & 2004-2005 & DAPT \\
\hline Silber et al. [11] & 455 & 1080 & RCT & - & DAPT \\
\hline Simek et al. [12] & $231+147+111$ & $573+465+436$ & Cohort & $2002-2009$ & DAPT \\
\hline $\begin{array}{l}\text { Total no. of } \\
\text { patients }(n)\end{array}$ & 2273 & 6251 & & & \\
\hline
\end{tabular}

ITDM insulin-treated diabetes mellitus, NITDM non-insulin-treated diabetes mellitus, $R C T$ randomized-controlled trials, $D A P T$ dual antiplatelet agents (aspirin and clopidogrel)

Table 3 Participants' baseline features

\begin{tabular}{llllll}
\hline Studies & $\begin{array}{l}\text { Age (years) } \\
\text { ITDM/NITDM }\end{array}$ & $\begin{array}{l}\text { Males (\%) } \\
\text { ITDM/NITDM }\end{array}$ & $\begin{array}{l}\text { HTN (\%) } \\
\text { ITDM/NITDM }\end{array}$ & $\begin{array}{l}\text { DS (\%) } \\
\text { ITDM/NITDM }\end{array}$ & $\begin{array}{l}\text { CS (\%) } \\
\text { ITDM/NITDM }\end{array}$ \\
\hline Banning et al. [6] & $65.4 / 65.4$ & $71.0 / 71.0$ & $69.9 / 69.9$ & $81.5 / 81.5$ & $15.8 / 15.8$ \\
Jain et al. [7] & $66.6 / 64.9$ & $62.2 / 71.8$ & $82.1 / 77.5$ & $67.9 / 67.7$ & $13.9 / 18.0$ \\
Jiang et al. [8] & $65.1 / 66.8$ & $72.1 / 74.2$ & $75.0 / 76.1$ & $79.4 / 78.0$ & $25.0 / 22.8$ \\
Kereiakes et al. [9] & $63.3 / 63.3$ & $63.3 / 63.3$ & $87.0 / 87.0$ & $82.5 / 82.5$ & $18.3 / 18.3$ \\
Nakamura et al. [10] & $66.2 / 67.2$ & $66.2 / 75.4$ & $68.1 / 72.0$ & $58.0 / 60.4$ & $12.1 / 19.5$ \\
Silber et al. [11] & $64.6 / 65.5$ & $56.4 / 70.4$ & $91.6 / 86.0$ & $86.8 / 86.0$ & $17.2 / 18.6$ \\
Simek et al. [12] & $65.1 / 65.1$ & $69.2 / 69.2$ & $70.6 / 70.6$ & $65.5 / 65.5$ & $32.1 / 32.1$ \\
\hline
\end{tabular}

ITDM insulin-treated diabetes mellitus, NITDM non-insulin-treated diabetes mellitus, $H T N$ hypertension, DS dyslipidemia, $C S$ current smoker

Evidence of publication bias was minimal across the studies that were involved in assessing early and late stent thrombosis in the patients with ITDM and NITDM, as shown in Figs. 4 and 5.

\section{DISCUSSION}

Previous meta-analyses based on ITDM patients with cardiac problems were well appreciated $[2,13]$.
Nevertheless, even though the authors assessed stent thrombosis in their previous work, this particular outcome was not assessed in detail. We therefore came up with the new idea of systematically comparing early, late and very late stent thrombosis post-PCI in patients with ITDM and NITDM.

In the previous analysis, stent thrombosis was shown to be significantly higher in patients with ITDM compared with NITDM (OR 1.66, $95 \%$ CI $1.16-2.38, P=0.005$ for short-term ST; 


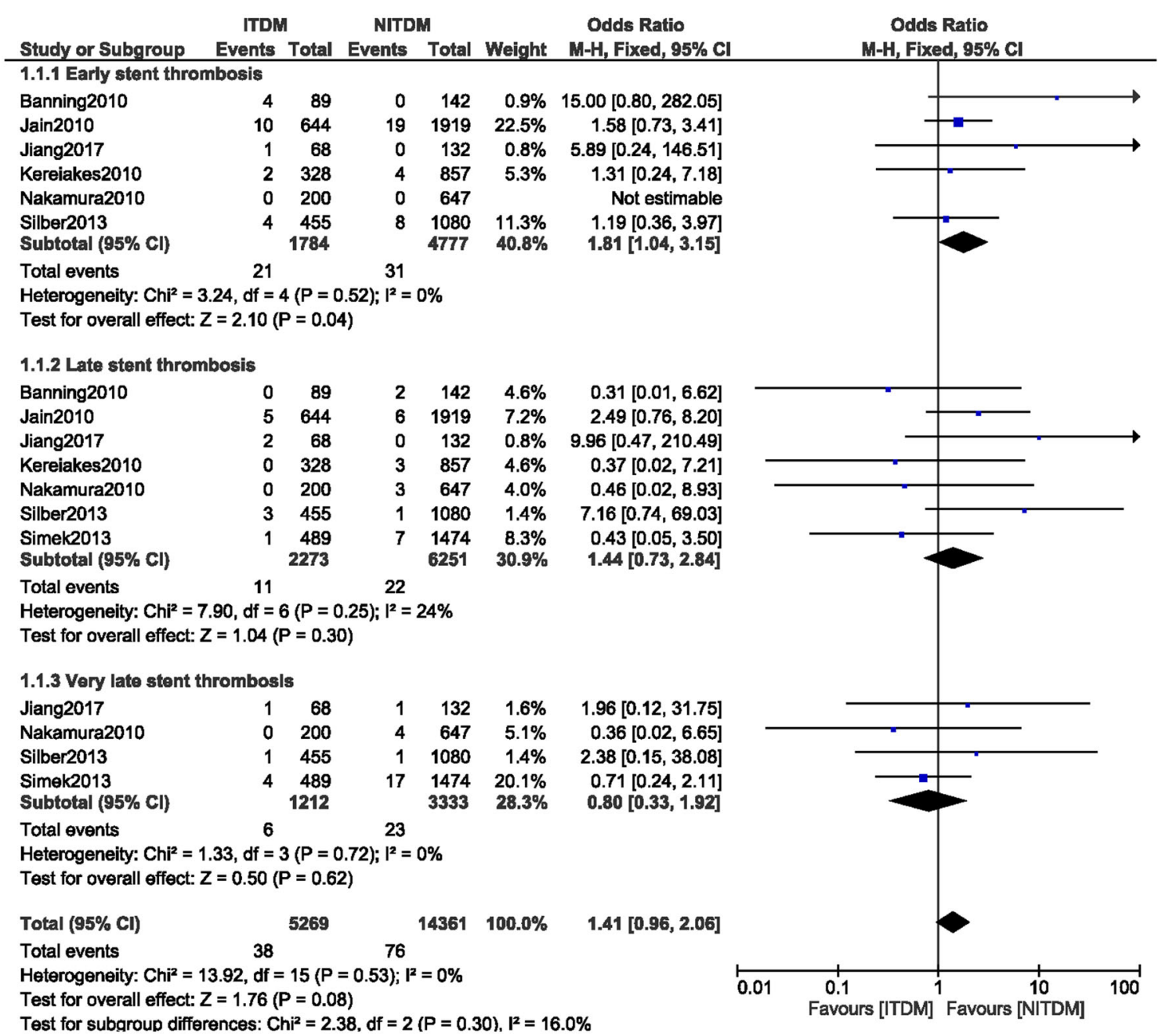

Fig. 2 Early, late and very late stent thrombosis in patients with type 2 diabetes mellitus who were treated with versus without insulin following percutaneous coronary intervention with drug-eluting stents

OR $1.59,95 \%$ CI $1.21-2.10 ; P=0.001$ for longterm ST) [2].

When data were closely assessed, it could be seen that stent thrombosis was definitely significantly higher in patients with ITDM compared with NITDM. This result was obtained when definite and probable or possible stent thromboses were analyzed all together. However, in the current analysis, when stent thrombosis was assessed based on the time period following PCI, early stent thrombosis was significantly higher in patients with insulin therapy (OR 1.81, 95\% CI 1.04-3.15; $P=0.04$ ). However, late (OR 1.44, 95\% CI $0.73-2.84 ; P=0.30)$ and very late stent thromboses (OR 0.80, 95\% CI $0.33-1.92$;
$P=0.62$ ) were not significantly different in patients with ITDM and NITDM.

Several reasons have been suggested for the high level of stent thrombosis in patients with ITDM: Patients on insulin therapy have more advanced disease, and their risk of complications after PCI is higher according to their high risk profile. Also, iatrogenic hyperinsulinemia might promote proinflammatory macrophage responses and stimulate hormonal hyperactivity, which might in return disturb the balanced synthesis and release of endothelial mediators. Insulin therapy might also cause platelet hyperactivity, which can then increase the chance of stent thrombosis after PCI with DES. 


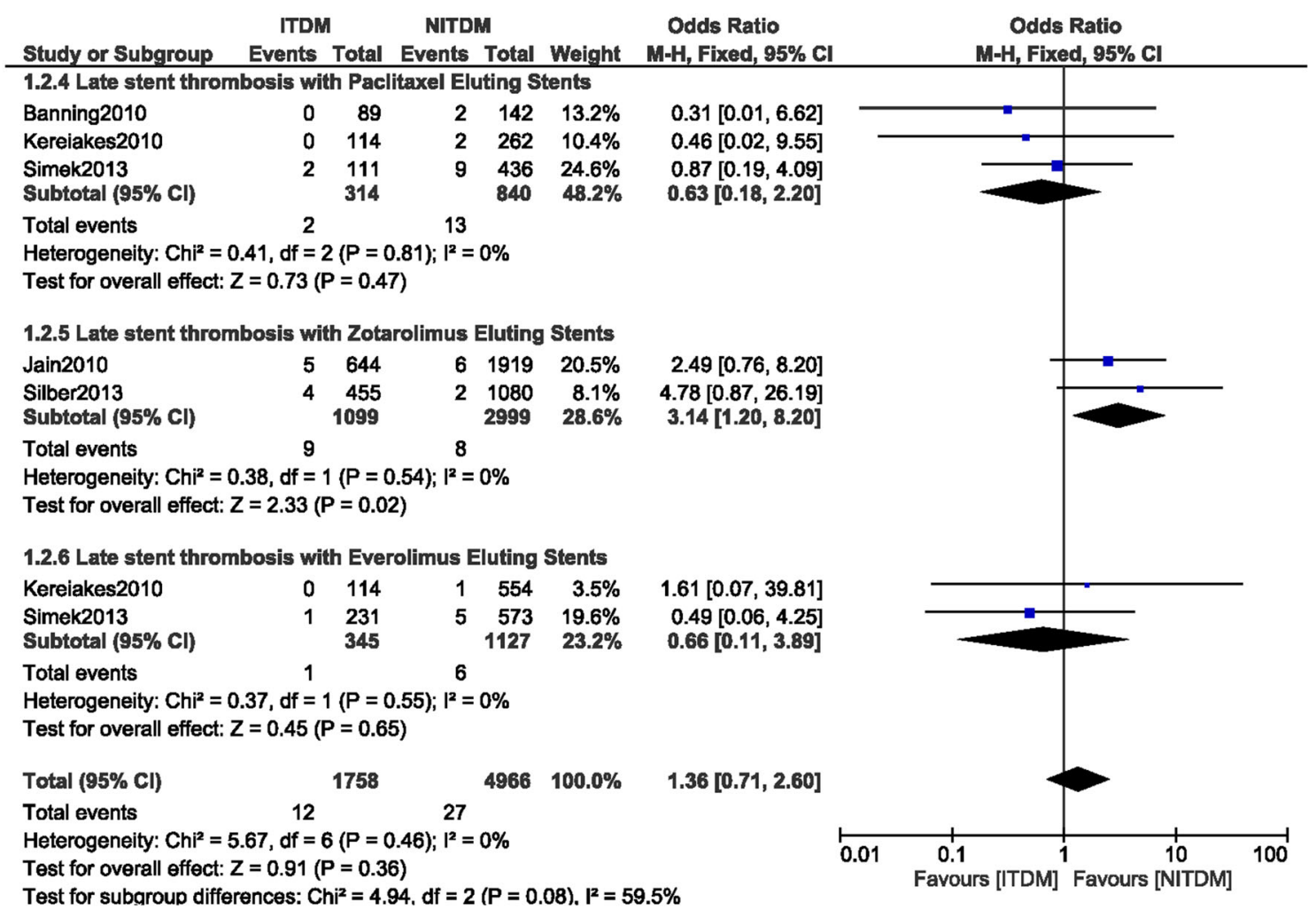

Fig. 3 Late stent thrombosis in patients with insulin-treated versus non-insulin-treated type 2 diabetes mellitus with individual drug-eluting stents (EES, PES, ZES)

Reasons that have been considered for a similar rate of late and very late stent thrombosis in this analysis could be that:

1. The total number of studies reporting these outcomes were few and not sufficient to reach a robust result in terms of very late stent thromboses, which were only reported in four studies;

2. This issue is controversial, and the number of studies favoring ITDM was similar to the number of studies favoring NITDM, resulting in an insignificant result for favoring either ITDM or NITDM in case of late and very late stent thrombosis;

3. The total number of early stent thromboses in patients with ITDM was indeed higher compared with late and very late stent thrombosis.

In other studies where early and late stent thromboses were reported following PCI in patients with and without insulin therapy, for example, in the E-five registry [7], 14 patients out of a total of $644(2.17 \%)$ patients with ITDM experienced stent thrombosis as defined by the Academic Research Consortium (ARC), whereas 25 out of 1919 (1.30\%) patients with NITDM experienced stent thrombosis as defined by the ARC. However, when stent thrombosis was further divided into early and late stent thrombosis, $1.6 \%$ of patients with ITDM experienced early stent thrombosis and $1.0 \%$ of the patients with NITDM experienced early stent thrombosis, whereas $0.8 \%$ and $0.3 \%$ of the patients with ITDM and NITDM, respectively, experienced late ST. Even if the percentage of patients with ITDM experienced more thrombosis, the percentage was reduced when stent thrombosis was further divided, especially in the case of late stent thrombosis.

The results of the SPIRIT IV Trial were different from those of the E-five registry [9]. The early stent thrombosis rate was $0.48 \%$ with EES in ITDM and $0.85 \%$ with PES in ITDM, and 

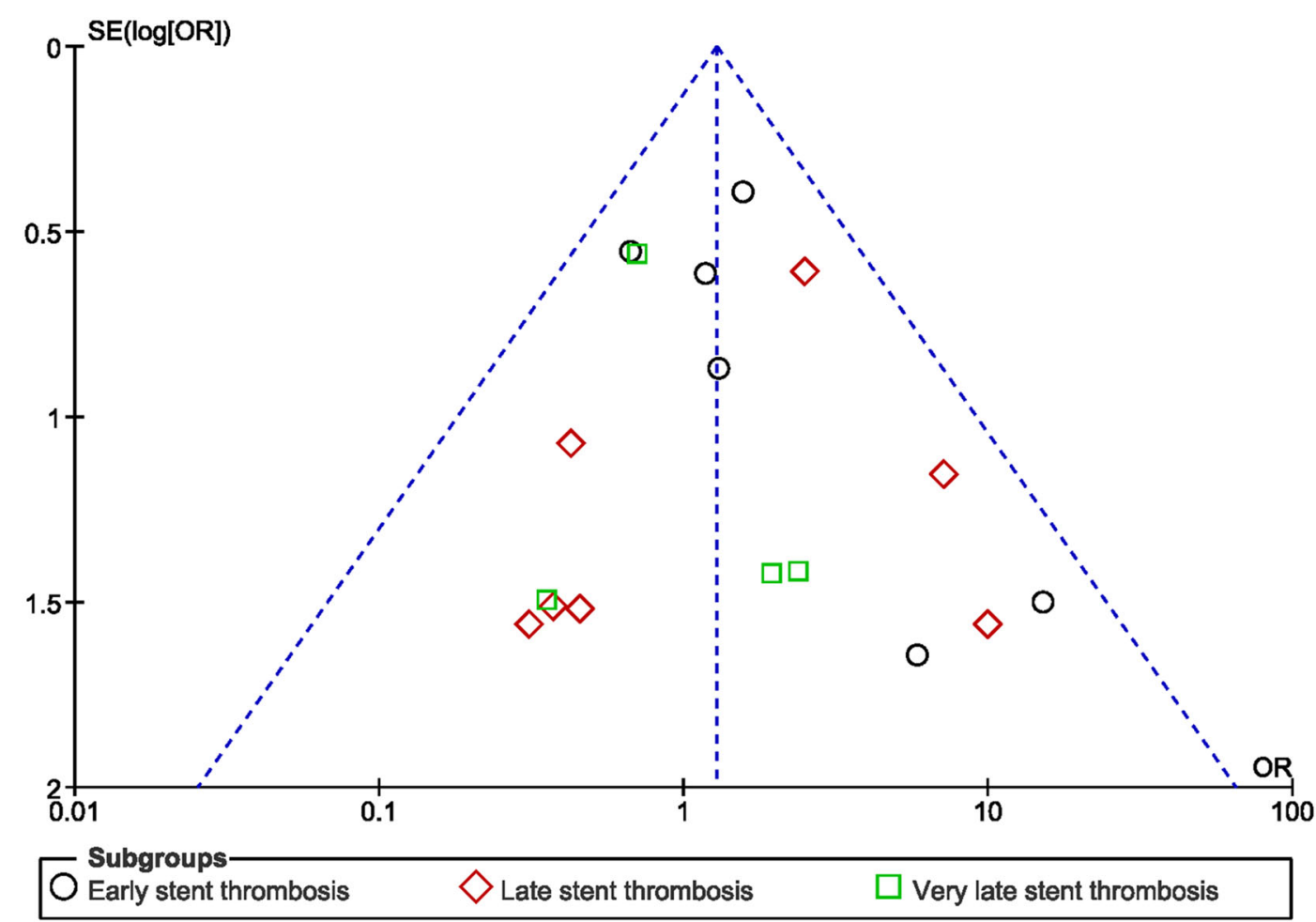

Fig. 4 Funnel plot showing publication bias (A)

there was no late stent thrombosis in ITDM. However, in patients with NITDM, early stent thrombosis was $0.35 \%$ with EES and $0.36 \%$ with PES, whereas late stent thrombosis was $0.18 \%$ with EES and $0.76 \%$ with PES. A conclusion could be that there was no late stent thrombosis in patients with ITDM who were implanted with DES.

In the 2-year results from the Prospectively Pooled Analysis of the International Global RESOLUTE Program [11], 0.9\% of patients with ITDM and $0.8 \%$ of patients with NITDM experienced early stent thrombosis, whereas $0.2 \%$ and $0.1 \%$ of patients with ITDM and NITDM, respectively, experienced late stent thrombosis. The number of patients who experienced late stent thrombosis events was similar between the ITDM and NITDM groups, further supporting this analysis.

In contrast, insights from a sub-study of the Cypher Stent Japan Post-Marketing Surveillance (Cypher J-PMS) Registry [10] showed no early, late or very late stent thrombosis in the ITDM group, whereas in patients with NITDM, 0.45\% and $0.62 \%$ patients experienced late and very late stent thrombosis, respectively, which partly contributed to the results that were obtained.

Nevertheless, following the previously published research article [2] based on patients with ITDM and NITDM post PCI, and upon reader requests, this analysis has further shown a new outcome, whereby early stent thrombosis was significantly higher in ITDM patients compared with those with NITDM, whereas late and very late stent thromboses were not significantly different in patients with ITDM and NITDM. This scientific concept should be of significant clinical importance and definitely find a place in medical libraries.

Finally, while recent analyses have focused on different types of drug-eluting stents and the associated stent thrombosis [14, 15], future analysis should compare stent thrombosis in male versus female patients with diabetes mellitus [16], specifically in male and female patients with ITDM and NITDM. In addition, 


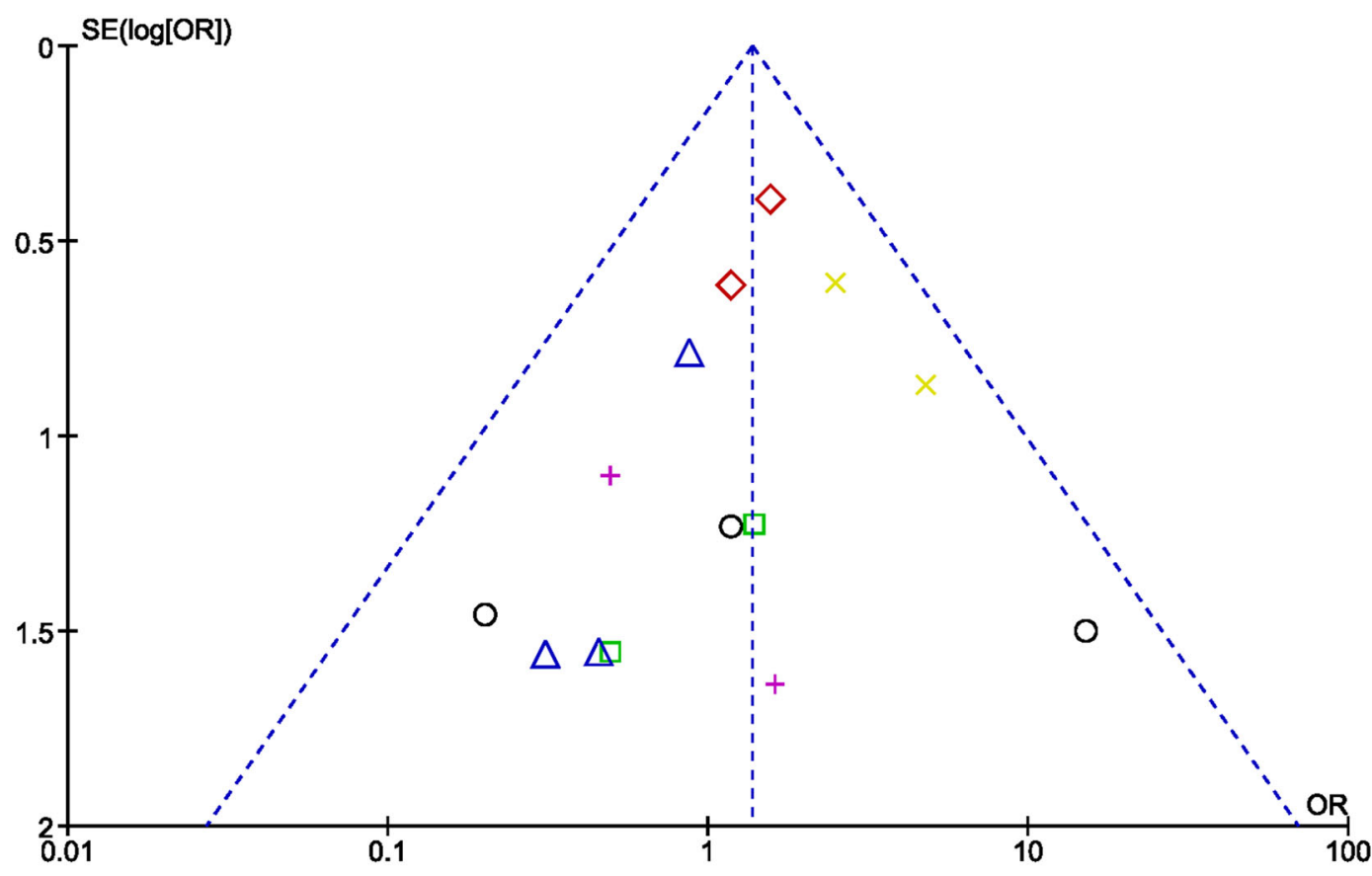

Subgroups

Early stent thrombosis with Paclitaxel Eluting Stents

$\checkmark$ Early stent thrombosis with Zotarolimus Eluting Stents

$\square$ Early stent thrombosis with Everolimus Eluting Stents

$\triangle$ Late stent thrombosis with Paclitaxel Eluting Stents

$X$ Late stent thrombosis with Zotarolimus Eluting Stents

+ Late stent thrombosis with Everolimus Eluting Stents

Fig. 5 Funnel plot showing publication bias (B)

the SYNTAX score $[17,18]$ should be included in future studies with ITDM and NITDM patients, and stent thrombosis should be assessed in patients with a low versus a high SYNTAX score.

\section{Limitations}

Limitations were:

1. Although the total number of patients was sufficient to reach a conclusion based on patients who were treated with DES as a whole, the number of patients was not sufficient to reach a conclusion when each DES (EES, SES, PES, ZES) was individually assessed.

2. First- and second-generation DESs were combined and analyzed assuming that they are all DESs; this could also have influenced the results.

3. For those studies that had a follow-up period $>1$ year, it was not known whether DAPT was continued or discontinued. This might also have influenced the results.

\section{CONCLUSIONS}

Following PCI with DES, early stent thrombosis was significantly higher in patients with ITDM. However, late and very late stent thromboses were not significantly different in patients with type 2 diabetes mellitus who were treated with or without insulin. Comparison with individual DESs was not sufficiently powerful to reach a conclusion. 


\section{ACKNOWLEDGEMENTS}

We thank the participants in the study.

Funding. No funding or sponsorship was received for this study or publication of this article. The article processing charges were funded by the authors.

Authorship. All named authors meet the International Committee of Medical Journal Editors (ICMJE) criteria for authorship for this article, take responsibility for the integrity of the work as a whole and have given their approval for this version to be published.

Author Contributions. Wei Chen, Yubin $\mathrm{Wu}$ and Yubao $\mathrm{Hu}$ were responsible for the conception and design, acquisition of data, analysis and interpretation of data, drafting the initial manuscript and revising it critically for important intellectual content. Dr. Wei Chen is the first author and wrote and approved the final manuscript.

Disclosures. The authors Wei Chen, Yubin $\mathrm{Wu}$ and Yubao $\mathrm{Hu}$ have nothing to disclose.

Compliance with Ethics Guidelines. This meta-analysis is based on previously conducted studies and does not contain any studies with human participants or animals performed by any of the authors.

Data Availability. All data generated or analyzed during this study are included in this published article.

Open Access. This article is distributed under the terms of the Creative Commons Attribution-NonCommercial 4.0 International License (http://creativecommons.org/licenses/ by-nc/4.0/), which permits any noncommercial use, distribution, and reproduction in any medium, provided you give appropriate credit to the original author(s) and the source, provide a link to the Creative Commons license, and indicate if changes were made.

\section{REFERENCES}

1. Oikonomou E, Mourouzis K, Fountoulakis P, Papamikroulis GA, Siasos G, Antonopoulos A, Vogiatzi G, Tsalamadris S, Vavuranakis M, Tousoulis D. Interrelationship between diabetes mellitus and heart failure: the role of peroxisome proliferatoractivated receptors in left ventricle performance. Heart Fail Rev. 2018. https://doi.org/10.1007/ s10741-018-9682-3.

2. Bundhun PK, Li N, Chen MH. Adverse cardiovascular outcomes between insulin-treated and noninsulin treated diabetic patients after percutaneous coronary intervention: a systematic review and meta-analysis. Cardiovasc Diabetol. 2015;7(14):135.

3. Modi K, Bhimji SS. Stent thrombosis. Treasure Island: StatPearls Publishing; 2018 (Internet).

4. Higgins JP, Thompson SG, Deeks JJ, et al. Measuring inconsistency in meta-analyses. BMJ. 2003;327:557-60.

5. Liberati A, Altman DG, Tetzlaff J, et al. The PRISMA statement for reporting systematic reviews and meta-analyses of studies that evaluate health care interventions: explanation and elaboration. BMJ. 2009;339:b2700.

6. Banning AP, Westaby S, Morice MC, Kappetein AP, Mohr FW, Berti S, Glauber M, Kellett MA, Kramer RS, Leadley K, Dawkins KD, Serruys PW. Diabetic and nondiabetic patients with left main and/or 3-vessel coronary artery disease: comparison of outcomes with cardiac surgery and paclitaxel-eluting stents. J Am Coll Cardiol. 2010;55(11):1067-75.

7. Jain AK, Lotan C, Meredith IT, Feres F, Zambahari R, Sinha N, Rothman MT, E-Five Registry Investigators. Twelve-month outcomes in patients with diabetes implanted with a zotarolimus-eluting stent: results from the E-Five Registry. Heart. 2010;96(11):848-53.

8. Jiang YJ, Han WX, Gao C, Feng J, Chen ZF, Zhang J, Luo CM, Pan JY. Comparison of clinical outcomes after drug-eluting stent implantation in diabetic versus nondiabetic patients in China: a retrospective study. Medicine (Baltim). 2017;96(17):e6647.

9. Kereiakes DJ, Cutlip DE, Applegate RJ, Wang J, Yaqub M, Sood P, Su X, Su G, Farhat N, Rizvi A, Simonton CA, Sudhir K, Stone GW. Outcomes in diabetic and nondiabetic patients treated with everolimus- or paclitaxel-eluting stents: results from the SPIRIT IV clinical trial (Clinical Evaluation of the XIENCE V Everolimus Eluting Coronary Stent System). J Am Coll Cardiol. 2010;56(25):2084-9.

10. Nakamura M, Yokoi H, Hamazaki Y, Watarai M, Kijima M, Mitsudo K, Cypher J-PMS Investigators. 
Impact of insulin-treated diabetes and hemodialysis on long-term clinical outcomes following sirolimus-eluting stent deployment. Insights from a sub-study of the Cypher Stent Japan Post-Marketing Surveillance (Cypher J-PMS) Registry. Circ J. 2010;74(12):2592-7.

11. Silber S, Serruys PW, Leon MB, Meredith IT, Windecker S, Neumann FJ, Belardi J, Widimsky P, Massaro J, Novack V, Yeung AC, Saito S, Mauri L. Clinical outcome of patients with and without diabetes mellitus after percutaneous coronary intervention with there solute zotarolimus-eluting stent: 2-year results from the prospectively pooled analysis of the international global RESOLUTE program. JACC Cardiovasc Interv. 2013;6(4):357-68.

12. Simsek C, Räber L, Magro M, Boersma E, Onuma Y, Stefanini GG, Zanchin T, Kalesan B, Wenaweser P, Jüni P, van Geuns RJ, van Domburg RT, Windecker $\mathrm{S}$, Serruys PW. Long-term outcome of the unrestricted use of everolimus-eluting stents compared to sirolimus-eluting stents and paclitaxel-eluting stents in diabetic patients: the Bern-Rotterdam diabetes cohort study. Int J Cardiol. 2013;170(1):36-42.

13. Munnee K, Bundhun PK, Quan H, Tang Z. Comparing the clinical outcomes between insulin-treated and non-insulin-treated patients with type 2 diabetes mellitus after coronary artery bypass surgery: a systematic review and meta-analysis. Medicine (Baltim). 2016;95(10):e3006.
14. Bundhun PK, Soogund MZ, Pursun M, Chen MH. Stent thrombosis and adverse cardiovascular outcomes observed between six months and five years with sirolimus-eluting stents and other drug-eluting stents in patients with Type 2 diabetes mellitus complicated by coronary artery disease: a systematic review and meta-analysis. Medicine (Baltim). 2016;95(27):e4130.

15. Bundhun PK, Pursun M, Teeluck AR, Long MY. Are everolimus-eluting stents associated with better clinical outcomes compared to other drug-eluting stents in patients with type 2 diabetes mellitus?: a systematic review and meta-analysis. Medicine (Baltim). 2016;95(14):e3276.

16. Bundhun PK, Pursun M, Huang F. Are women with type 2 diabetes mellitus more susceptible to cardiovascular complications following coronary angioplasty?: a meta-analysis. BMC Cardiovasc Disord. 2017;17(1):207.

17. Bundhun PK, Sookharee Y, Bholee A, Huang F. Application of the SYNTAX score in interventional cardiology: a systematic review and meta-analysis. Medicine (Baltim). 2017;96(28):e7410.

18. Bundhun PK, Bhurtu A, Huang F. Worse clinical outcomes following percutaneous coronary intervention with a high SYNTAX score: a systematic review and meta-analysis. Medicine (Baltim). 2017;96(24):e7140. 